\title{
Detecting acute reperfusion myocardial hemorrhage with CMR: a translational study
}

\author{
Avinash Kali ${ }^{1,2^{*}}$, Andreas Kumar ${ }^{3}$, Richard L Tang ${ }^{2}$, Rohan Dharmakumar ${ }^{2}$ \\ From 15th Annual SCMR Scientific Sessions \\ Orlando, FL, USA. 2-5 February 2012
}

\section{Background}

Hemorrhage is a frequent hallmark of large acute reperfused myocardial infarctions (rMI). Recently, there has been a growing interest in CMR for noninvasive detection of hemorrhage in rMI. While T2*- and T2-weighted CMR have been used for this purpose, there is a lack of consensus on which of these methods is the most appropriate and reliable. We investigated the relative abilities of T2 and T2* CMR for detecting hemorrhage in $\mathrm{rMI}$ in a canine model and patients.

\section{Methods}

Canines $(n=14)$, subjected to ischemia-reperfusion ( $I / R)$ injury ( 3 hrs of LAD occlusion followed by reperfusion), underwent CMR (1.5T) studies on day 5 post reperfusion. T2*-weighted (multi GRE; TE=3.4-18.4ms (6 echoes)), T2-weighted (T2-prep SSFP; prep times $=0,24$ and $55 \mathrm{~ms}$ ), T2-STIR (TE=64 ms) and Late Enhancement (LE) images covering the LV were acquired. Imaging resolution of all the scans was $1.3 \times 1.3 \times 8 \mathrm{~mm} 3$.

Patients $(\mathrm{n}=14)$ underwent CMR (1.5T) on day 3 post angioplasty for STEMI after providing informed consent. T2*-weighted ( $\mathrm{TE}=2.6-13.8 \mathrm{~ms}$ ( 6 echoes)), T2-STIR ( $\mathrm{TE}=61 \mathrm{~ms}$ ) and LE images covering the LV were acquired. Imaging resolution of all the scans was $1.4 \times 1.4 \times 10 \mathrm{~mm} 3$.

$\mathrm{T} 2 *$ and $\mathrm{T} 2$ maps were constructed by fitting the multi-echo data to monoexponential decay. A thresholdbased signal analysis was used to identify hemorrhagic (Hemo+) and non-hemorrhagic (Hemo-) infarcts. T2STIR signal intensity (STIR-SI), T2* and T2 values, measured from Remote, Hemo- and Hemo+ regions, were compared. Statistical significance was set at $\mathrm{p}<0.05$.

\footnotetext{
'Biomedical Engineering, University of California, Los Angeles, Los Angeles, CA, USA

Full list of author information is available at the end of the article
}

\section{Results}

Representative $\mathrm{T}^{*}$ and T2 maps, and T2-STIR and LE images (acquired from a canine on day 5 post I/R injury) are shown in Fig. 1A. Mean T2* of Hemo+ was lower than both Remote and Hemo- regions (-39\%; $\mathrm{p}<0.001$; Fig. $1 \mathrm{~B}$ and $1 \mathrm{C})$, while no differences were observed in $\mathrm{T}^{*}$ between Remote and Hemo- $(\mathrm{p}=0.27)$. Compared to Remote, mean T2 of both Hemo- and Hemo+ regions were elevated $(26 \%$ and $17 \%$ respectively; $\mathrm{p}<0.001$ ), with T2 of Hemo-greater than T2 of Hemo+ $(\mathrm{p}<0.001)$. A similar trend was observed in T2STIR images as well; STIR-SI of Hemo+ and Hemowere greater than Remote (59\% and 31\% respectively; $\mathrm{p}<0.001$ ), while STIR-SI of Hemo- was greater than Hemo+ $(\mathrm{p}<0.001)$.

Representative T2* map, T2-STIR and LE images, acquired from a patient (day 3 post angioplasty) are shown in Figure 2. Consistent with the animal studies, mean $\mathrm{T}_{2} *$ of $\mathrm{Hemo}+$ was lower than the mean $\mathrm{T}^{*}$ of both Remote and Hemo- $(-46 \%, \mathrm{p}<0.001$; Fig.2), while no differences were observed between $\mathrm{T} 2 *$ of Remote and Hemo- $(\mathrm{p}=0.61)$. Mean STIR-SI of both Hemo- and Hemo+ were greater than that of Remote (78\% and 33\% respectively; $\mathrm{p}<0.001)$, with the mean STIR-SI of Hemogreater than that of Hemo+ $(\mathrm{p}<0.001)$.

\section{Funding}

This work was supported in part by grants from American Heart Association (SDG 0735099N) and National Heart, Lung, And Blood Institute (HL091989).

\footnotetext{
Author details

'Biomedical Engineering, University of California, Los Angeles, Los Angeles, CA, USA. ${ }^{2}$ Biomedical Sciences, Cedars-Sinai Medical Center, Los Angeles, CA, USA. ${ }^{3}$ Québec Heart and Lung Institute, Laval University, Québec City, QC, Canada, USA.
}

Published: 1 February 2012 


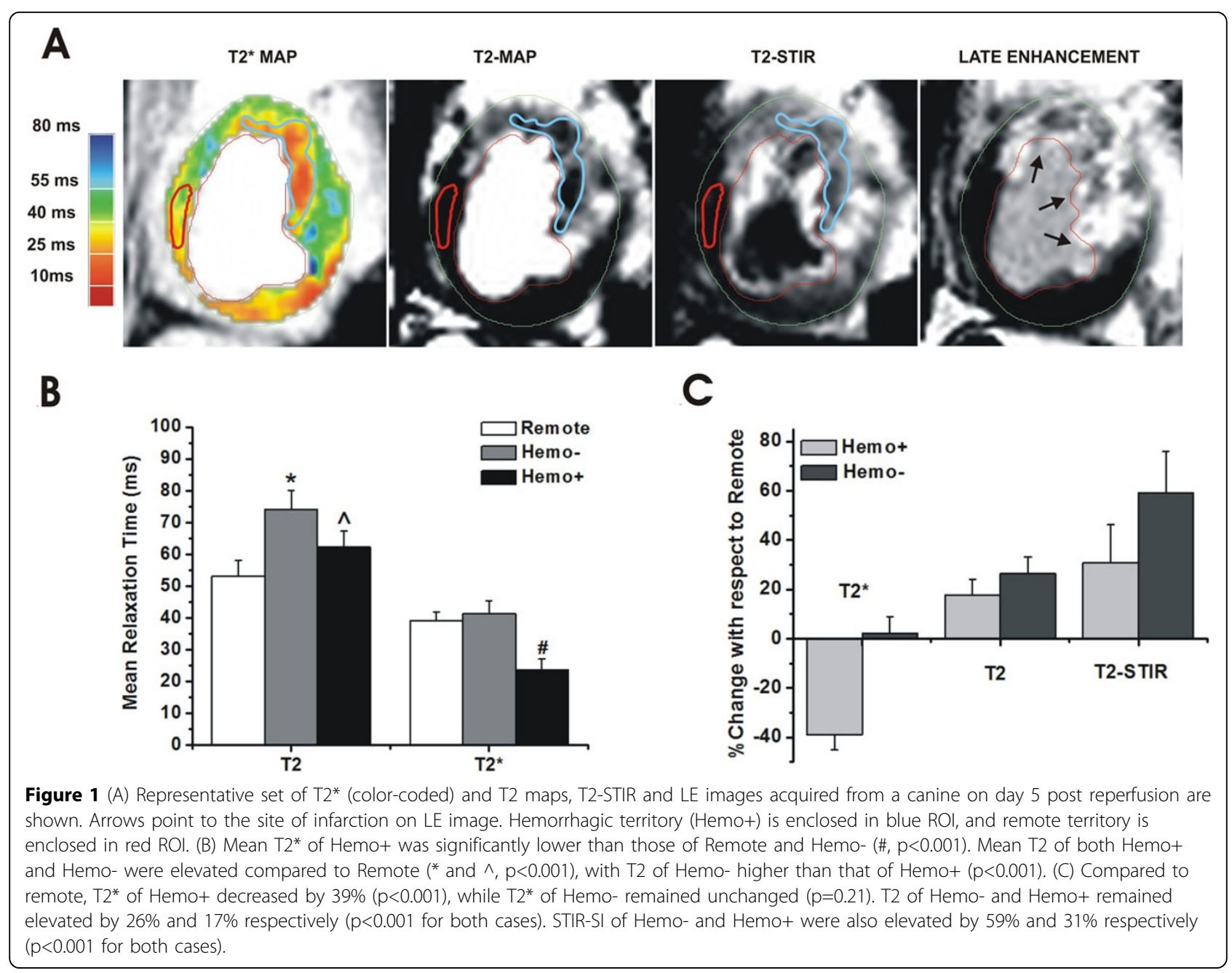

doi:10.1186/1532-429X-14-S1-061

Cite this article as: Kali et al:: Detecting acute reperfusion myocardial hemorrhage with CMR: a translational study. Journal of Cardiovascular Magnetic Resonance 2012 14(Suppl 1):O61.

\section{Submit your next manuscript to BioMed Central} and take full advantage of:

- Convenient online submission

- Thorough peer review

- No space constraints or color figure charges

- Immediate publication on acceptance

- Inclusion in PubMed, CAS, Scopus and Google Scholar

- Research which is freely available for redistribution 